\section{The ultra low frequency electromagnetic radiation observed in the topside ionosphere above boundaries of tectonic plates}

\author{
Michael A. Athanasiou, ${ }^{1,2}$ \\ Gergios C. Anagnostopoulos, ${ }^{3}$ \\ Constantinos N. David, 2 \\ Gregorios G. Machairidis ${ }^{4}$ \\ 'Department of Information \& \\ Communications, Technical University of \\ Serres, Serres; 'Department of \\ Mechanical Engineering, Technical \\ University of Serres, Serres; ${ }^{3}$ Department \\ of Electrical \& Computer Engineering, \\ Democritus University of Thrace, Xanthi; \\ ${ }^{4}$ Connect I.T., Informatics Company, \\ Xanthi, Greece
}

\section{Abstract}

In this paper we present results of a comparison between ultra low frequency (ULF) electromagnetic (EM) radiation, recorded by an electric field instrument onboard the satellite detection of electromagnetic emissions transmitted from earthquake regions in the topside ionosphere, and the seismicity of regions with high and low seismic activity. In particular, we evaluated the energy variations of the ULF Ezelectric field component during a period of four years (2006-2009), in order to examine the possible relation of ULF EM radiation with seismogenic regions located in Central America, Indonesia, the Eastern Mediterranean Basin and Greece. As a tool for evaluating the ULF Ez energy variations we used singular spectrum analysis techniques. The results of our analysis clearly show a significant increase of the ULF EM energy emitted from regions of highest seismic activity at the boundaries tectonic plates. Furthermore, we found that higher electromagnetic radiation was detected in a region above the northern-western Greek Arc (R1) than above the adjacent region including Athens and its urban area. We interpret these results of the present study as suggesting that: i) the seismogenic regions at the boundary of tectonic plates radiate ULF EM emissions observed by satellites in the topside ionosphere; and ii) that this EM radiation is not only related with the occurrence time of great $(M \geq 5)$ earthquakes, but it is often present in intermediate times and it appears as a quasi-permanent phenomenon.

\section{Introduction}

Although earthquakes (EQs) are known to be complex phenomena, there has been growing evidence in the last decades that EQs precursory phenomena can be detected. This evidence was based on studies of certain effects related to electric and magnetic fields, ionospheric perturbations, nightglow observations, electromagnetic (EM) emissions from direct currents to high frequency range and radiation belt electron precipitation in the topside ionosphere. ${ }^{1-6}$

During the preparation of earthquakes, many chemical materials emanate, such as radon and metal aerosols. According to the lithosphere-atmospere-ionosphere coupling (LAIC) model proposed by Pulinets and Ouzounov, ${ }^{7}$ the á-particles emitted by radon are converted finally in heat, and cause enormous amounts of energy release after the condensation/evaporation process. Pulinets ${ }^{5}$ further elaborated the physical mechanisms described by Pulinets and Ouzounov ${ }^{7}$ and attempted to demonstrate the LAIC as a complex system, being a derivative of the intensive radon activity before earthquakes start to demonstrate anomalies in the atmosphere, ionosphere and magnetosphere at times when the system approaches the critical state. On the other hand, acoustic gravity waves are considered to be generated before and after an earthquake at the ground-atmosphere boundary. ${ }^{8}$ These waves propagate in the atmosphere, penetrate into the atmosphere, and then disturb plasma parameters in the lower ionosphere. ${ }^{9}$

Theoretical studies and laboratory experiments suggest that deformations of rocks under special pressure and temperature conditions exist in the brittle seismogenic crust, which destabilise the mechanical and electrical properties of the solids. In particular, according to the electromechanical mechanism, electric charges are generated as the result of friction and a piezoelectric phenomenon that changes the Earth's electric field and generates EM waves, which are considered to propagate to the upper atmosphere and ionosphere. ${ }^{10-13}$

The study on seismogenic ultra low frequency (ULF) emissions started in the early 1990s. Even though the radio emissions are generated as a pulse in the earthquake hypocenter, higher frequency components cannot propagate over long distances in the lithosphere due to severe attenuation. Only ultralow and extremely low frequency (ULF/ELF) waves can reach the Earth's surface Hayakawa. ${ }^{14}$ Freund ${ }^{15}$ suggests that during the build-up of stress before EQs, charge carriers are able to flow out of the stressed rock volume into surrounding rocks. Such outflow constitutes an electric cur-
Correspondence: Gergios C. Anagnostopoulos, Department of Electrical \& Computer Engineering, Democritus University of Thrace, Panepistimioupoli Kimmeria, Building B, 67100 Xanthi, Greece.

Tel.: +30.25410 .79986 - Fax: +30.25410 .79590 .

E-mail: ganagno@ee.duth.gr

Key words: seismo-electromagnetic effects, Earth's electromagnetic ultra low frequency radiation, electromagnetic perturbations, seismic precursors, ionospheric, earthquake-related satellite observations.

Acknowledgments: the authors thank $\mathrm{Dr}$ Berthelier for providing the DEMETER/ICE data and Dr M. Parrot for his comments on a part of the manuscript.

Funding: this study was supported by the NSRF 2007-2013 Thales - Hellenic National Network for Space Weather Research (HNSWRN) - MIS 377274 project of the Greek Ministry of Education, Lifelong Learning and Religious Affairs - General Secretariat for Research and Technology and the Seismic Precursor Satellite Signals ( $2^{\text {nd }}$ Phase) Project of the Special Account of Democritus, University of Thrace. The financial support from the Research Committee of the Technical University (TEI) of Serres under grant 117/13/3.10.2012 is also gratefully acknowledged by the leading author.

Received for publication: 22 July 2013.

Revision received: 6 March 2014.

Accepted for publication: 6 July 2014.

This work is licensed under a Creative Commons Attribution NonCommercial 3.0 License (CC BYNC 3.0).

(OCopyright M.A. Athanasiou et al., 2014

Licensee PAGEPress, Italy

Research in Geophysics 2014; 4:5001

doi:10.4081/rg.2014.5001

rent, which generates EM signals. If the outflow occurs in bursts, it will lead to short EM pulses. If the outflow is continuous, the currents may fluctuate, generating EM emissions over a wide frequency range. Numerical computations suggest that ULF/ELF electromagnetic emissions lower than $20 \mathrm{~Hz}$ can transverse directly into the upper ionosphere. ${ }^{16}$

Indeed, from the 80's until now, dozens of studies regarding several seismic events have been presented validating the existence of EM wave emission during seismic activity. ${ }^{17,18}$ Nevertheless, bearing in mind the relatively few statistical analyses which have been done, the corresponding results still seem to be ambiguous. Only a part of them have shown a temporal and spatial correlation between the EM waves and the seismic events. ${ }^{2,19,20}$ So, the question whether there is a relationship between the seismic activity of an area and the EM radiation in the space over this specific area is still open. ${ }^{21}$ In this study we are further 
elaborating the above question.

Specifically, instead of studying the ULF EM wave activity around the time of an earthquake occurrence near its epicentre, we compare the ULF EM wave energy in the topside ionosphere with the seismic activity of various geographic regions of historically high seismicity, including boundaries of tectonic plates. Our study focuses on certain regions such as the Eastern Mediterranean Sea, Central America, Indonesia and Greece. The results decisively support a spatial correlation between strong $\left[\geq 0.02(\mathrm{mV} / \mathrm{m})^{2}\right]$ ULF EM radiation and the seismogenic regions examined around the boundaries of tectonic plates.

\section{Materials and Methods}

The satellite DEMETER (Detection of Electro-Magnetic Emissions Transmitted from Earthquake Regions) was launched on June $29^{\text {th }}, 2004$. Its orbit altitude is $710 \mathrm{~km}$, and it takes 14 orbits per day around the Earth. Among the scientific objectives of the DEMETER mission is the investigation of ionospheric disturbances due to seismic and volcanic activities.

In this study we analyze DEMETER ULF data recorded by the electric field instrument (ICE) sensors onboard the satellite. ${ }^{22}$ Most specifically, we estimate the energy of the electric field Z-component $\mathrm{E}_{\mathrm{z}}$ of ULF EM waves radiated within the frequency range $<20 \mathrm{~Hz}$ as they were recorded by the ICE experiment for a period of four years (2006-2009) during the satellite overnight passes above some seismogenic regions of great interest. The energy was estimated in successive orbit segments of $2^{\circ}$ latitude range, under the condition that the middle of the orbit segment is located within the defined region under study. Each $2^{\circ}$ latitude orbit segment with enhanced EM is considered a separate ULF event.

In order to estimate the EM energy, we developed a novel method that comprises two stages: first we filter the signal and we keep only the very low frequencies in the given DEMETER/ICE range $<20 \mathrm{~Hz}$, and then eliminate its trend using techniques of singular spectrum analysis combined with a thirddegree polynomial filter. ${ }^{18,23}$ Signals with electromagnetic energy $\mathrm{E} \leq 0.02(\mathrm{mV} / \mathrm{m})^{2}$ have not been included in our study because of their minimal impact on the results.

In Figure 1 we give a representative example of the ULF signals considered in our study. Figure 1A shows the waveform of Ez electric field component during the time interval 20:20:20 - 20:30:25, 2007/02/17 (orbit 140 $\left.33 \_1\right)$. A green line in the Figure 1 indicates a significant fluctuation in the Ez component waveform over Greece (Figure 1B), observed by ICE/DEMETER between 20:25:00 - 20:27:00 $\mathrm{UT} / 37^{\circ}-39^{\circ}$ lat. The results of our filtering method applied to this signal is shown in Figure 1C; the energy fluctuation shown in Figure 1D was found to reach a value as high as $0.21(\mathrm{mV} / \mathrm{m})^{2}$.

\section{Results}

\section{The case of seismicity in Greece}

\section{Western-Eastern Greece}

The outstanding seismicity of Greece (the country is ranked third worldwide and first among the countries of the European continent) is due to its special geological features, which are shaped by the movements of the Eurasian, African and Anatolian tectonic plates in the Eastern Mediterranean basin. This region of high seismicity is known as the Greek Arc and is shown in Figure 2A (the seismic map has been constructed by the University of Athens for earthquakes with magnitude $M \geq 4$ in the years 2000-2008). Here

(a)

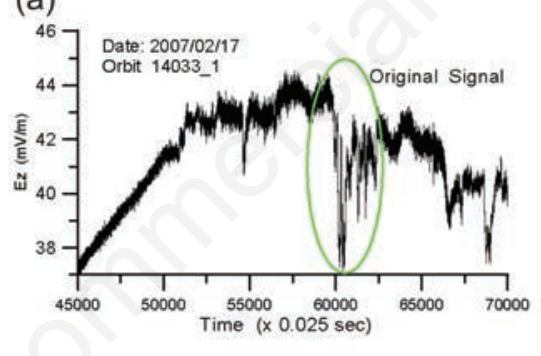

(c)

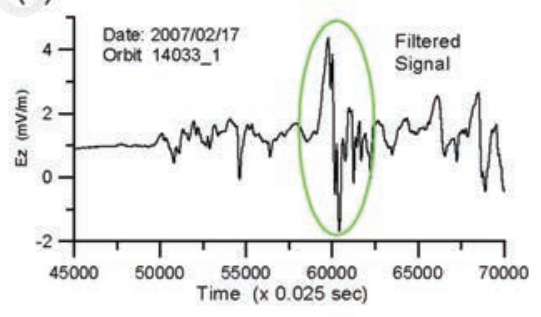

we examine the northwest part of the Greek Arc, a rectangular region with latitudes between $\mathrm{N} 36^{\circ}-39^{\circ}$ and longitudes $\mathrm{E} 19^{\circ}-22^{\circ}$ (seismic region marked as $\mathrm{R} 1$ ). As we can see in Figure 2A, the region $\mathrm{R} 1$ (marked by the red border line) shows stronger seismic activity, between the years 2000 and 2008, than its eastern neighbouring region $\mathrm{R} 2$ (marked by green border line). Given that both of the areas (R1 and R2) have the same latitude, they absorb comparable solar energy and have equivalent geomagnetic conditions.

During a period of four years (2006-2009) a sample of 41 ULF events with energy $E \geq 0.02$ $(\mathrm{mV} / \mathrm{m})^{2}$ were recorded above both regions $\mathrm{R} 1$ and $\mathrm{R} 2$, which are shown by solid circles in Figure 2B. The size of the circles shown in the figure compared with the numerical scale of the label inserted at the bottom of the figure indicates the amount of energy of the corresponding ULF electromagnetic radiation.

From the sample of 41 ULF events, a number of 28 events were recorded above region $\mathrm{R} 1$ of historically high seismicity, whereas only 13 events were detected above the adjacent region $\mathrm{R} 2$ of low seismicity. The corresponding

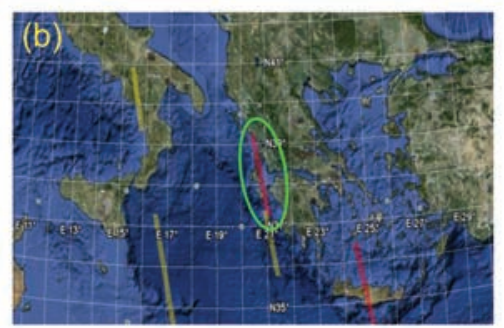

(d)

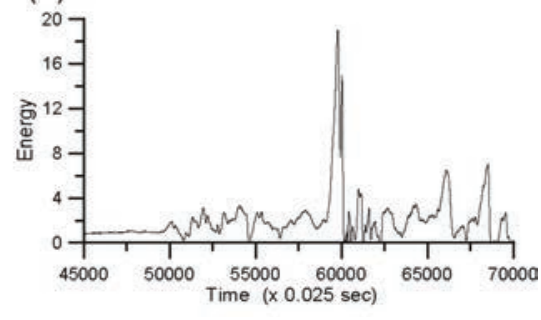

Figure 1. A) The waveform of Ez electric field component during the DEMETER's orbit 14033_1 for the time interval 20:20:20-20:30:25 UT, 17/02/2007. The ultra low frequency event is indicated by the green elipse. $B$ and $C$ ) The green elipse indicates the position of the specific observation and of the filtered signal in time. D) The energy of the filtered signal.

Table 1. Total energy of the ultra low frequency electromagnetic waves expressed in $(\mathrm{mV} / \mathrm{m})^{2}$ in Western-Eastern Greece.

\begin{tabular}{lccccc} 
Western-Eastern Greece & \multicolumn{5}{c}{ Years } \\
& 2006 & 2007 & 2008 & 2009 & $2006-2009$ \\
Region R1 Total energy (ER1) & 0.20 & 0.77 & 0.75 & 0.05 & 1.77 \\
Region R2 Total energy (ER2) & 0.12 & 0.04 & 0.33 & 0.09 & 0.58 \\
\hline ER1/ER2 & 1.67 & 19.25 & 2.27 & 0.55 & 3.05 \\
\hline
\end{tabular}


total emitted energy from the two examined regions was $\mathrm{E}_{1}=1.77(\mathrm{mV} / \mathrm{m})^{2}$ and $\mathrm{E}_{2}=0.58$ $(\mathrm{mV} / \mathrm{m})^{2}$ respectively. Hence the ratio of the emitted energy from R1 and R2 is $E_{1} / E_{2}=3.05$. Table 1 shows the values of the total emitted ULF energy from regions R1 and R2 and for the years 2006-2009, as well as per year. As we can see the emitted energy was permanently higher above R1 than above R2 for each year, except for year 2009 when the ULF energy was very low for both areas.

In a following step, in order to further elaborate the possible relationship between the recorded ULF EM emission and the seismicity of the examined regions, we studied a smaller sample characterized by the most intense ULF events. Thereby, from the initial sample we rejected the records with energy lower than $0.08(\mathrm{mV} / \mathrm{m})^{2}$. Thus, only 9 ULF events remained $(\sim 2.09 \%$ of the total number of events). From these, 7 events are related with the region R1, while only 2 events with the region $\mathrm{R} 2$. In addition we found that the total energy from the two regions amounts to $\mathrm{E}_{1}=0.96(\mathrm{mV} / \mathrm{m})^{2}$ and $\mathrm{E}_{2}=0.22(\mathrm{mV} / \mathrm{m})^{2}$ respectively. These values give a ratio $\mathrm{E}_{1} / \mathrm{E}_{2}=4.36$, which compared to the ratio $\mathrm{E}_{1} / \mathrm{E}_{2}=3.05$ (sample of 41 events), emphasize that the ULF EM energy observed by DEMETER in the topside ionosphere is positively related to the seismic activity of the examined regions R1 and R2.

Figure $2 \mathrm{C}$ and D illustrate the total energy of both considered areas in relation to longitude by means of normalized histograms. It is obvious that the total energy over the area R1, which is characterized by higher seismic activity, is greater than the corresponding energy emitted from area R2 with lower seismicity.

\section{Southern Crete}

The region of southern Crete is considered to be one of the most seismogenic regions of the globe; the so-called Hellenic arch passes near it (Figure 3). Figure 3A shows the $M>4.5$ seismic activity of the region for the time period of the years 2006-2009. We see that region $\mathrm{R} 8$, with latitude boundaries $\mathrm{N} 33^{\circ}-35^{\circ}$ and longitude $\mathrm{E} 23^{\circ}-28^{\circ}$, is more seismogenic than the adjacent regions $\mathrm{R} 7$ and $\mathrm{R} 9$, although the latter have the same latitude (longitude limits E $18^{\circ}-23^{\circ}$ and $\mathrm{E} 28^{\circ}-33^{\circ}$, respectively). During the period of four years (2006-2009) a sample of 33 ULF events with energy 0.02-0.14 $(\mathrm{mV} / \mathrm{m})^{2}$ were recorded above regions $\mathrm{R} 7, \mathrm{R} 8$ and R9 (Figure 3B).

In the region R8, with the most seismicity, 18 events were recorded, with total energy of 0.96 units. In the left (right) region R7 (R9) with low seismicity, 10 (5) events were recorded, with total energy $0.53(0.20)$ units. The corresponding total energies of the signals, as shown in Table 2, were found to be $\mathrm{E} 7=0.53$ $(\mathrm{mV} / \mathrm{m})^{2}$ for region $\mathrm{R} 7, \mathrm{E} 8=0.96(\mathrm{mV} / \mathrm{m})^{2}$ for region $\mathrm{R} 8$ and $\mathrm{E} 9=0.2(\mathrm{mV} / \mathrm{m})^{2}$ for region $\mathrm{R} 9$.

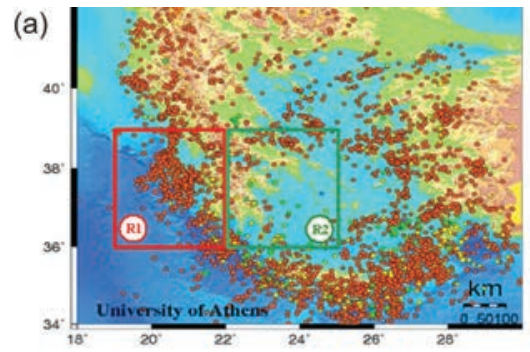

(c)

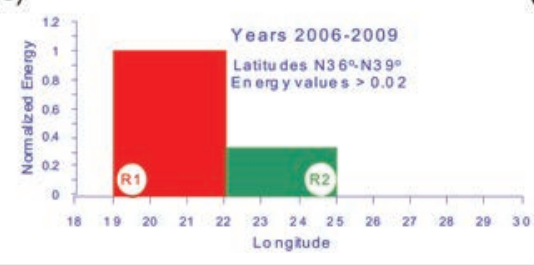

(b)

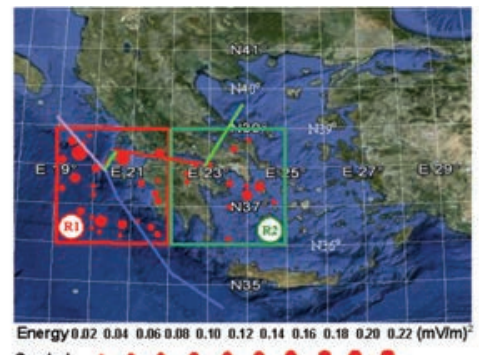

(d)

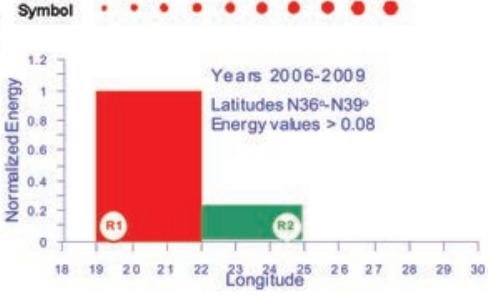

Figure 2. A) Seismicity map of Greece for the years 2000-2008 illustrating earthquakes of magnitude $M>4$. B) Location and energy of the ultra low frequency (ULF) electromagnetic radiation acquired by the DEMETER satellite for the years 2006-2009. C) Normalized energy of ULF electromagnetic (EM) radiation in the areas $R 1, R 2$ for values $\geq 0.02(\mathrm{mV} / \mathrm{m})^{2}$. D) Normalized energy of ULF EM radiation in the areas $R 1, R 2$ for values $\geq 0.08(\mathrm{mV} / \mathrm{m})^{2}$.
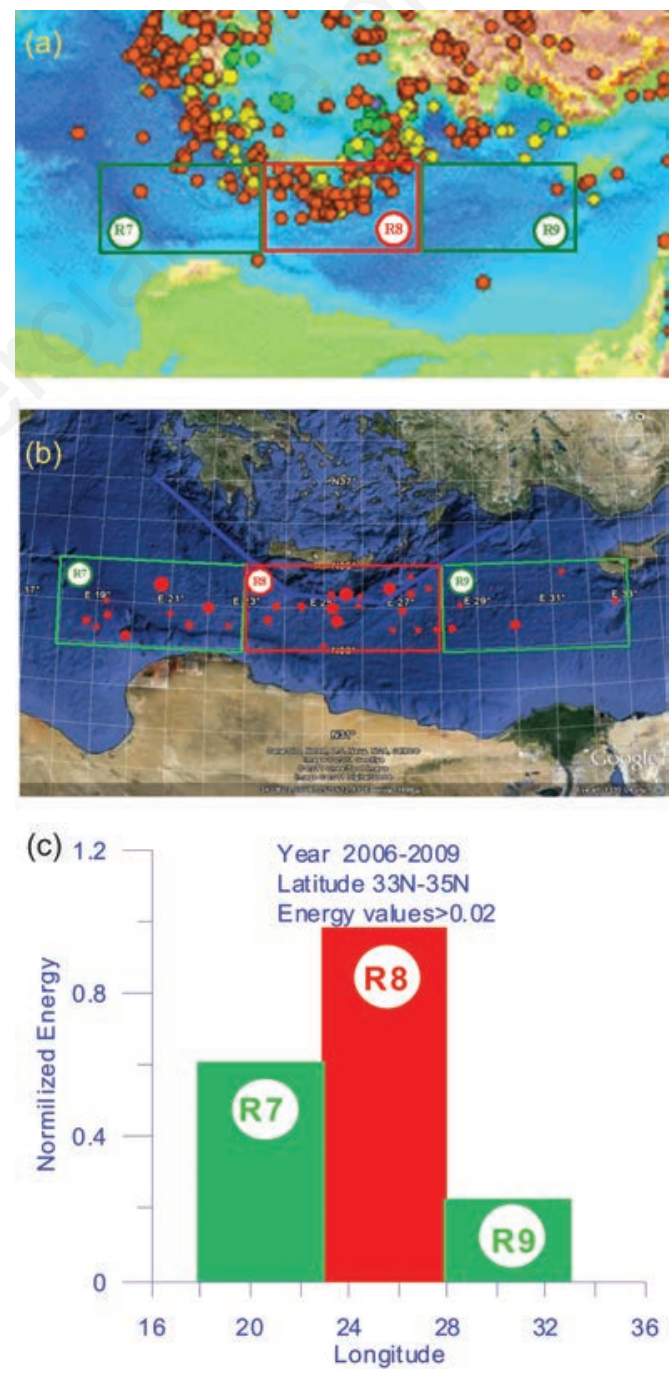

Figure 3. A) Seismicity map of Crete for the years 2000-2009 illustrating earthquakes of magnitude $M>4.5$. B) Location and energy of the ultra low frequency (ULF) electromagnetic radiation acquired by the DEMETER satellite for the years 2006-2009. C) Normalized energy of ULF electromagnetic radiation in the areas R7, R8, R9, for values $\geq$ than $0.02(\mathrm{mV} / \mathrm{m})^{2}$. 
We see that the highest energy emission was recorded in region $\mathrm{R} 8$, where also the highest seismic activity (Figure $3 \mathrm{~A}$ ) is observed. The ratio of the total energy over region $\mathrm{R} 8$ to the total energy over the adjacent regions $\mathrm{R} 7$ and $\mathrm{R} 9$ is $\mathrm{E} 8 / \mathrm{E} 7=1.81$ and $\mathrm{E} 8 / \mathrm{E} 9=4.8$. In Table 2 the values of the total ULF energy measure above regions $R 7, R 8$ and $R 9$ for the total period 2006 2009 along with the ULF energy for each year 2006-2009 are shown. As we can see the observed energy was in general higher above $\mathrm{R} 8$ than above R7, R9 for each year; only in the year 2007 was the ULF energy the same for both areas R7, R8.

The histogram in Figures 3C illustrates the normalized total energy of regions R7, R8 and R9. It is obvious that the total energy above area $\mathrm{R} 8$, is greater than the corresponding energy observed above areas R7 and R9. These results suggest that the highest energy was observed by DEMETER above the area with the highest seismic activity. In addition, we note that the total energy of the ULF events in the region $\mathrm{R} 8$ (with the highest seismicity among R7, R8 and R9) was found to be 2.83 times higher compared to the average energy of the adjacent regions $\mathrm{R} 7$ and $\mathrm{R} 9$.

\section{Southern-northern Crete}

Because of the location of the Hellenic Arc, the southern region of Crete is more seismogenic than the northern region (Figure 2A). Figure 4A shows the seismic activity of a broad region including Crete, for the time period 2000-2009; the solid circles in the figure show the epicentres of $E Q s$ with $M \geq 4.5$. Two adjacent regions have been marked, named R10 and $\mathrm{R} 11$ respectively, at latitudes between $33.30^{\circ}-35^{\circ}$ (southern region) and $35^{\circ}-36.30^{\circ}$ (northern region) and with common longitudes $\left(24^{\circ}-27^{\circ}\right)$. From Figure $4 \mathrm{~A}$ it is evident that region $\mathrm{R} 10$ is more seismogenic than the adjacent region R11. During the period of four years (2006-2009) a sample of 14 ULF signal events with energy of $0.02-0.12(\mathrm{mV} / \mathrm{m})^{2}$ was recorded above regions $\mathrm{R} 10$ and $\mathrm{R} 11$ and are shown in Figure 4B (the size of the solid circles correspond to the amount of energy). We observe that the strongest signals were recorded in region $\mathrm{R} 10$ with the most seismicity. In region R10 (R11) $10^{4}$ signals were recorded with a total energy of $0.69(0.17)(\mathrm{mV} / \mathrm{m})^{2}$ (Table 3). We also note that the ratio of the total energy of the recorded ULF events over the region R10 to the total energy over the adjacent region $\mathrm{R} 11$ is $\mathrm{E} 10 / \mathrm{E} 11=4.05$; these results obviously suggest that higher energy was recorded above the region of higher seismicity (region 10 ).

Figure 4C has been constructed as Figure $3 \mathrm{C}$ and its histogram indicates the large difference in the ULF energy observed above regions R10-R11, with much higher values above region $\mathrm{R} 10$ than above region $\mathrm{R} 11$. The com-
Table 2. Total energy of the ultra low frequency electromagnetic waves expressed in $(\mathrm{mV} / \mathrm{m})^{2}$ in Southern Crete.

\begin{tabular}{lccccc} 
Greece-Southem Crete & 2006 & 2007 & 2008 & 2009 & $2006-2009$ \\
\hline Region R7 Total energy (ER7) & 0 & 0.21 & 0.1 & 0.22 & 0.53 \\
Region R8 Total energy (ER8) & 0.27 & 0.19 & 0.15 & 0.35 & 0.96 \\
\hline Region R9 Total energy (ER9) & 0.09 & 0 & 0 & 0.11 & 0.20 \\
ER8/ER7 & $>>1$ & 0.9 & 1.5 & 1.59 & 1.81 \\
\hline ER8/ER9 & 3 & $>>1$ & $>>1$ & 3.18 & 4.80 \\
\hline
\end{tabular}

Table 3. Total energy of the ultra low frequency electromagnetic waves expressed in $(\mathrm{mV} / \mathrm{m})^{2}$ in Southern and Northern Crete.

\begin{tabular}{lc} 
Greece-Southern and Northern Crete & Years 2006-2009 \\
Region R10 Total energy (ER10) & 0.69 \\
Region R11 Total energy (ER11) & 0.17 \\
\hline ER10/ER11 & 4.05 \\
\hline
\end{tabular}
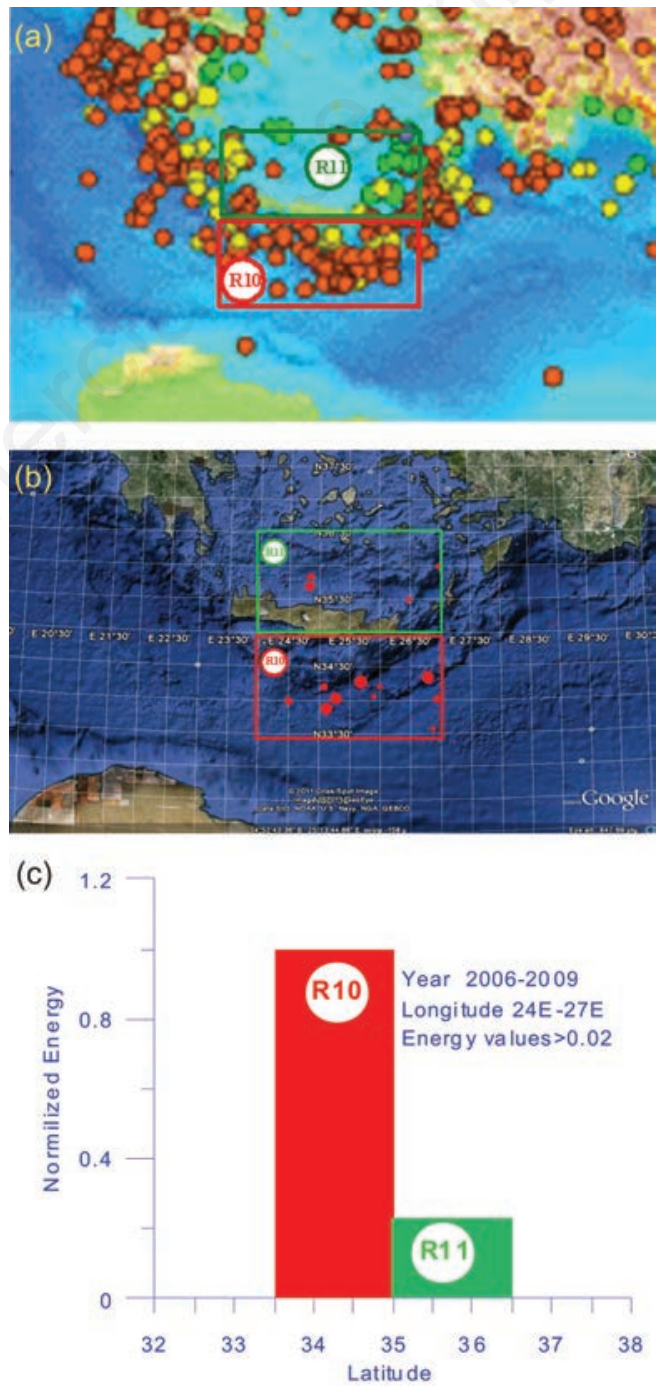

Figure 4. A) Seismicity map of Crete for the years 2000-2009 illustrating earthquakes of magnitude $M>4.5$. B) Location and energy of the ultra low frequency (ULF) electromagnetic radiation acquired by the DEMETER satellite for the years 2006-2009. C) Normalized energy of ULF electromagnetic radiation in the areas R10, R11, for values $\geq 0.02(\mathrm{mV} / \mathrm{m})^{2}$. 
parison of Figure 4 panels A-C strongly suggests that the stronger ULF radiation was observed above the most seismically active region (R10).

\section{Central America}

The next area we have studied covers part of Central America and the Pacific Ocean within the latitude range $\mathrm{N} 10^{\circ}-20^{\circ}$ and the longitude range $\mathrm{E} 215^{\circ}-275^{\circ}$. In Figure $5 \mathrm{~A}$ is shown the seismicity map of the above region for earthquakes with magnitude $M \geq 4.5$ and for the period 2000-2009 (sources: University of Athens and USGS). As is depicted on the map, the eastern region enclosed within the red borderline (marked as R3) has more intense seismic activity in comparison to the western region indicated by a green borderline (marked as R4). For a period of four years (2006-2009) a sample of 605 ULF events with energy $\mathrm{E} \geq 0.02$ $(\mathrm{mV} / \mathrm{m})^{2}$ were recorded by the satellite DEMETER during its night passes over the examined areas. From this sample, 416 events were recorded above region $\mathrm{R} 3$, whereas only 189 events were detected above region $\mathrm{R} 4$, while the corresponding total emitted energy was evaluated to be $\mathrm{E}_{3}=19.91(\mathrm{mV} / \mathrm{m})^{2}$ and $\mathrm{E}_{4}=7.96$ $(\mathrm{mV} / \mathrm{m})^{2}$, respectively. Representative results of the geographic distribution of the ULF events within the year 2008 are shown in Figure $5 \mathrm{~B}$. In the same figure the seismic fault lines of the region due to the movements of the tectonic plates (Pacific Plate, Cocos Plate, Caribbean Plate and North American Plate) are illustrated. It is obvious that a similar asymmetry in the distribution of the ULF events between areas R3 and R4 for the year 2008 was observed, as in the case during the whole period 2006-2009 discussed above. More explicitly, we found 108 events above region R3 [total energy $\mathrm{E}_{3}=5.44(\mathrm{mV} / \mathrm{m})^{2}$ ], but only 46 events above region $\mathrm{R} 4\left[\mathrm{E}_{4}=1.76(\mathrm{mV} / \mathrm{m})^{2}\right]$. In addition, it is worth noting that the density of the electromagnetic energy increases close to the fault lines of this seismogenic region.

Table 4 shows the ULF EM energy values regarding the examined regions $\mathrm{R} 3$ and $\mathrm{R} 4$ for the years 2006-2009 as well as per year. As we can see the total energy of the recorded ULF events during the whole period, as well as for each year is greater above region R3 (with higher seismic activity) than above region $\mathrm{R} 4$. Specifically, the ratio of the emitted energy from the regions R3 and R4 for the years 20062009 was found to be $E_{3} / E_{4}=2.5$.

Based on the methodology explained in the case of Western-Eastern Greece, when only the most intense $\left[\mathrm{E} \geq 0.08(\mathrm{mV} / \mathrm{m})^{2}\right]$ ULF events are taken into account (52 events, i.e. $0.36 \%$ of the total sample), an asymmetrical distribution regarding both the event numbers $\left(\mathrm{N}_{3}, \mathrm{~N}_{4}\right)$ and the total emitted energy $\left(\mathrm{E}_{3}, \mathrm{E}_{4}\right)$ for the regions $\mathrm{R} 3$ and $\mathrm{R} 4$ (E3/E4=3.7) was found. Thereafter $\mathrm{N}_{\mathrm{i}}$ is considered as the number of

ULF events and $\mathrm{E}_{\mathrm{i}}$ as the emitted ULF EM energy in the corresponding region $\mathrm{R}_{\mathrm{i}}$. [ In this case $\mathrm{N}_{3}=42, \mathrm{~N}_{4}=10, \mathrm{E}_{3}=5.47(\mathrm{mV} / \mathrm{m})^{2}$ and $\mathrm{E}_{4}=1.48$ $\left.(\mathrm{mV} / \mathrm{m})^{2}\right]$. This asymmetry is similar to the case we examined above $\left[\mathrm{E} \geq 0.02(\mathrm{mV} / \mathrm{m})^{2}\right]$, but with a higher ratio of the observed energies.

Figure 5C and D show the normalized histograms of the total energy of both considered regions. It is obvious that the total energy over area $\mathrm{R} 3$, which is characterized by higher seismic activity, is greater than the corresponding energy emitted from area R4 with lower seismic activity.

Table 4. Total energy of the ultra low frequency electromagnetic waves expressed in $(\mathrm{mV} / \mathrm{m})^{2}$ in Central America.

\begin{tabular}{lccccc} 
Central America & & \multicolumn{5}{c}{ Years } \\
& 2006 & 2007 & 2008 & 2009 & $2006-2009$ \\
Region R3 Total energy (ER3) & 3.36 & 3.89 & 5.44 & 7.22 & 19.91 \\
Region R4 Total energy (ER4) & 2.60 & 1.91 & 1.76 & 1.69 & 7.96 \\
\hline ER3/ER4 & 1.29 & 2.03 & 3.09 & 4.27 & 2.5 \\
\hline
\end{tabular}

Table 5. Total energy of the ultra low frequency electromagnetic waves expressed in $(\mathrm{mV} / \mathrm{m})^{2}$ in Indonesia.

\begin{tabular}{lccccc} 
Indonesia & & \multicolumn{5}{c}{ Years } \\
& 2006 & 2007 & 2008 & 2009 & $2006-2009$ \\
Region R5 Total energy (ER5) & 2.19 & 1.44 & 1.82 & 1.77 & 7.22 \\
Region R6 Total energy (ER6) & 0.65 & 0.98 & 0.49 & 1.38 & 3.50 \\
\hline ER5/ER6 & 3.36 & 1.47 & 3.71 & 1.28 & 2.06 \\
\hline
\end{tabular}

(a)

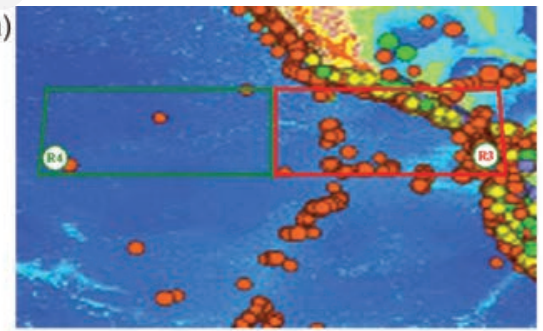

(c)

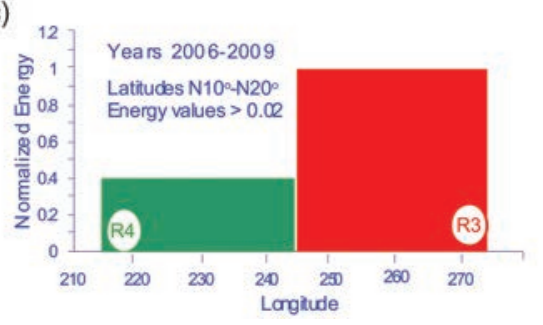

\section{Indonesia}

Figure 6 has been constructed in the same format as Figure 5 concerning a large region of Indonesia, between lat. $0^{\circ}-\mathrm{S} 10^{\circ}$ and long. $\mathrm{E}$ $80^{\circ}-110^{\circ}$ and for earthquakes of magnitude $M \geq 4.5$ for the years $2000-2009$. As we can see (Figure 6A) the seismic activity is much higher in region $\mathrm{R} 5$ (E $95^{\circ}-110^{\circ}$ ) compared to region $\mathrm{R} 6\left(\mathrm{E} 80^{\circ}-95^{\circ}\right)$ due to the complexity of the boundaries of the Australian-Indian and Eurasian tectonic plates. In this case $245 \mathrm{ULF}$ events with energy $\mathrm{E} \geq 0.02(\mathrm{mV} / \mathrm{m})^{2}$ were selected by our algorithm. Among them 156 were recorded above region $\mathrm{R} 5$ [total emitted energy $\mathrm{E}_{5}=7.22(\mathrm{mV} / \mathrm{m})^{2}$ ] and only 89 events detected above region $\mathrm{R} 6\left[\mathrm{E}_{6}=3.5(\mathrm{mV} / \mathrm{m})^{2}\right]$

Figure 5. A) Seismicity map of Central America for the years 2000-2009 illustrating earthquakes of magnitude $M>4.5$. B) Location and energy of the ultra low frequency (ULF) electromagnetic radiation acquired by the DEMETER satellite for the year 2008 . C) Normalized energy of ULF electromagnetic (EM) radiation in the areas R3, R4 for values greater than $0.02(\mathrm{mV} / \mathrm{m})^{2}$. D) Normalized energy of ULF EM radiation in the areas $\mathrm{R} 3, \mathrm{R} 4$ for values $\geq 0.08(\mathrm{mV} / \mathrm{m})^{2}$. 
respectively.

Figure $6 \mathrm{~B}$ demonstrates a representative sample of the geographical distribution of the recorded ULF events for the year 2006. We found 44 events above region R5 [total energy $\left.\mathrm{E}_{5}=2.19(\mathrm{mV} / \mathrm{m})^{2}\right]$, but only 22 events above region $\mathrm{R} 6\left[\mathrm{E}_{6}=0.65(\mathrm{mV} / \mathrm{m})^{2}\right]$. It is obvious that the density of the ULF events increases and the total observed energy apparently becomes higher over the main fault, which is depicted with a blue line.

Table 5 shows similar results with Table 1 concerning the regions R5 and R6. For the whole period 2006-2009 the ratio of the emitted energy from R5 and R6 was found to be $\mathrm{E}_{5} / \mathrm{E}_{6}=2.06$. As in the previous cases (Figures 2D and 4D), when only a set with the most intense [ $\left.\mathrm{E} \geq 0.08(\mathrm{mV} / \mathrm{m})^{2}\right]$ ULF events are considered ( $0.30 \%$ of the total sample), a similar asymmetry of the recorded energies is found, as for the events with energy $\mathrm{E} \geq 0.02(\mathrm{mV} / \mathrm{m})^{2}$, but with a higher ratio $\left(\mathrm{E}_{5} / \mathrm{E}_{6}=5.18\right)$. The numbers of the considered ULF events and the total emitted energies were $\mathrm{N}_{5}=18, \mathrm{~N}_{6}=4, \mathrm{E}_{5}=1.97$ $(\mathrm{mV} / \mathrm{m})^{2}$ and $\mathrm{E}_{6}=0.38(\mathrm{mV} / \mathrm{m})^{2}$ respectively. Figure $6 \mathrm{C}$ and $\mathrm{D}$ reveal a similar pattern for the electromagnetic energy observed above the more seismically active region compared to the cases presented in Figures 2-5.

Since the above examined regions ( $\mathrm{R} 5$ and R6) lie at one of the broader and most seismically active areas of the globe, in order to further prove our results we extended our study on a larger longitude range including the whole seismic region between Indonesia and Australia. For this reason we analyzed data for the region between lat. $\mathrm{S} 0^{\circ}-10^{\circ}$ and long. E $80^{\circ}-180^{\circ}$. This enlarged region includes a wide part of the boundaries of the Australian plate with the Eurasian and the Pacific plates of highest seismicity (Figure 7A; red coloured frame). The left and the right sub-regions of the drawn frame are characterized by lower seismic activity. Furthermore, for a detailed analysis, we divided the whole region into 10 geographical zones, with a longitude range of $10^{\circ}$ for each one. For the years 2006-2009, 171 events with energy $\mathrm{E} \geq 0.06(\mathrm{mV} / \mathrm{m})^{2}$ were found and the total recorded energy $\left(E_{7}\right)$ amounts $14.36(\mathrm{mV} / \mathrm{m})^{2}$.

Table 6 shows the number of ULF events over each geographical zone and the coresponding total recorded ULF electromagnetic energy. To facilitate a direct comparison of the emitted ULF wave energy with the seismic activity of the region R7, Figure 7B shows a histogram of the total energy, normalized at its maximum value for the 10 sub-regions. By comparing Figure 7A and B we can see a very good correlation between the density of large EQs and the total emitted ULF electromagnetic energy $\mathrm{E}_{7-\mathrm{i}}$, where the index $\mathrm{i}$ corresponds to the examined sub-regions (E $80^{\circ}-90^{\circ}$, E $90^{\circ}$ $\left.100^{\circ} \ldots \mathrm{E} 170^{\circ}-180^{\circ}\right)$. Additionally, in the zone
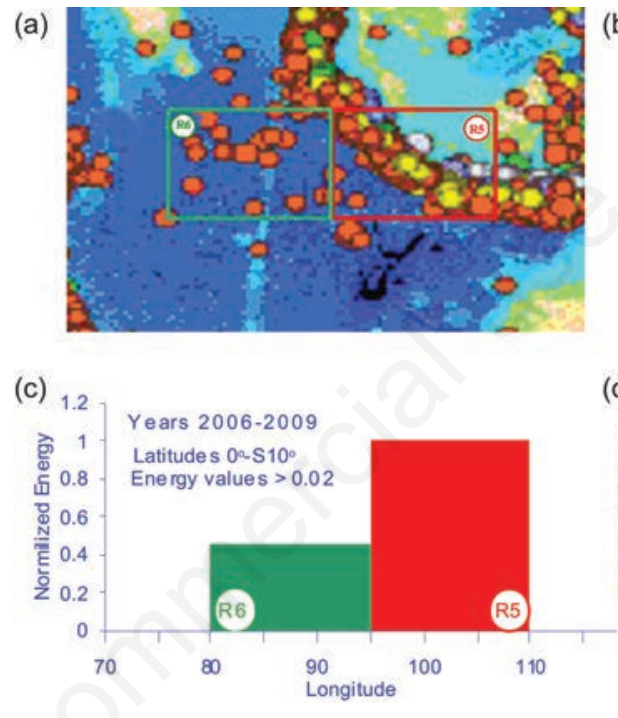

within the longitudes $\mathrm{E} 120^{\circ}-130^{\circ}$ the total energy becomes lower, which is possibly related with the fault disruption as is indicated by the blue line. The results are more evident if waves with total energy less than $0.12(\mathrm{mV} / \mathrm{m})^{2}$ are rejected, as shown in Table 6 and graphically illustrated in Figure 7C. In this case the total wave energy takes zero values over the zones with longitudes E $80^{\circ}-90^{\circ}$ and E $160^{\circ}$ $180^{\circ}$, while the energy decreasing in the zone with longitudes $\mathrm{E} 120^{\circ}-130^{\circ}$ becomes more obvious.

\section{Eastern Mediterranean Basin}

In our analysis we have presented a comparison of ULF electromagnetic wave activity above adjacent regions in three examples of highly seismic areas on the globe: Greece, Central America and Indonesia. More explicit-

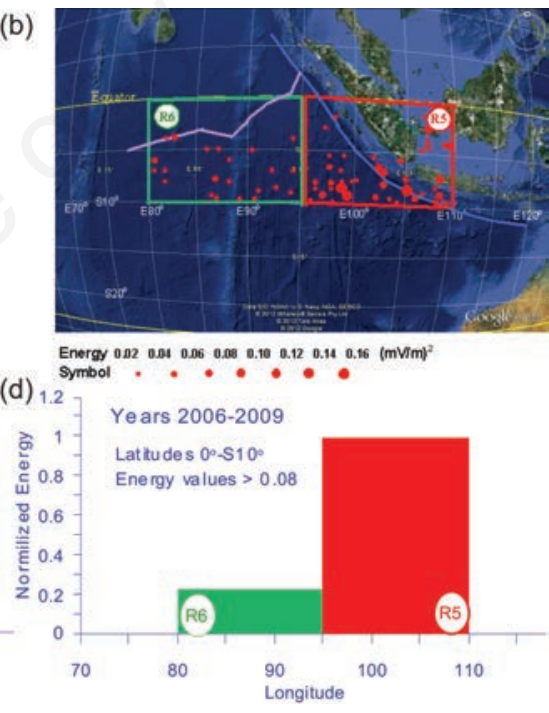

Figure 6. A) Seismicity map of Indonesia for the years 2000-2009 illustrating earthquakes of magnitude $M>4.5$. B) Location and energy of the ultra low frequency (ULF) electromagnetic radiation acquired by the DEMETER satellite for the years 2006. C) Normalized energy of ULF electromagnetic (EM) radiation in the areas R5, R6 for values greater than $0.02(\mathrm{mV} / \mathrm{m})^{2}$. D) Normalized energy of ULF EM radiation in the areas $\mathrm{R} 5$, R6 for values greater than $0.08(\mathrm{mV} / \mathrm{m})^{2}$.

Table 6. Total energy of the ultra low frequency electromagnetic radiation over Indonesia.

\begin{tabular}{lcccc} 
Longitude & $\begin{array}{c}\text { Energy threshold } 0.06(\mathrm{mV} / \mathrm{m})^{2} \\
\text { Total energy }\end{array}$ & $\begin{array}{c}\text { Energy threshold } 0.12(\mathrm{mV} / \mathrm{m})^{2} \\
\text { Tumber of events }\end{array}$ \\
E $80^{\circ}-90^{\circ}$ & 10 & 0.77 & 0 & 0 \\
E $90^{\circ}-100^{\circ}$ & 10 & 0.89 & 2 & 0.26 \\
\hline E $100^{\circ}-110^{\circ}$ & 25 & 2.23 & 4 & 0.55 \\
E $110^{\circ}-120^{\circ}$ & 24 & 1.92 & 2 & 0.25 \\
\hline E $120^{\circ}-130^{\circ}$ & 18 & 1.44 & 1 & 0.12 \\
E $130^{\circ}-140^{\circ}$ & 24 & 2.23 & 5 & 0.68 \\
\hline E $140^{\circ}-150^{\circ}$ & 24 & 2.04 & 4 & 0.52 \\
E $150^{\circ}-160^{\circ}$ & 23 & 1.88 & 2 & 0 \\
\hline E $160^{\circ}-170^{\circ}$ & 7 & 0.51 & 0 & 0 \\
E $170^{\circ}-180^{\circ}$ & 6 & 0.45 & 0 & 0 \\
\hline
\end{tabular}

Latitude: $0^{\circ}$-S10 $0^{\circ}$ Years: 2006-2009 
ly, we compared the ULF electromagnetic wave activity in two distinct regions in each of the three cases, with the one known as highly seismogenic and the adjacent one with low or very low seismic activity. Moreover, we have also mentioned that the ULF electromagnetic wave activity was higher in the vicinity of the earthquake faults of the regions examined. In this section we would like to further elaborate the question how the ULF electromagnetic wave activity varies when the satellite DEMETER passes close to the earthquake faults. As an example we examine the Eastern Mediterranean basin.

Figure 8A shows the geographical distribution of the ULF events with energy $\mathrm{E} \geq 0.02$ $(\mathrm{mV} / \mathrm{m})^{2}$ recorded by the satellite DEMETER during the period 2006-2009 over the Eastern Mediterranean Sea with latitude ranging between $33^{\circ}-41^{\circ}$ and longitude $16^{\circ}-36^{\circ}$. In Figure $8 \mathrm{~A}$, some concentrations of ULF events are quite evident: the southern Ionian Sea, the southern part of Crete and the northern border between Greece and Turkey (shaded by red). In this case we want to identify the DEMETER positions in which the highest ULF wave radiation is recorded. For this reason we show, in Figure $8 \mathrm{~B}$, only those events with energy $\mathrm{E} \geq 0.14(\mathrm{mV} / \mathrm{m})^{2}$. The majority of the intense ULF events (yellow colored cycles) is observed very close to the faults (9 over 12 i.e. $75 \%$ ). This finding demonstrates a correlation between the DEMETER positions where the highest ULF wave radiation has been recorded, with the characteristic regions of the wellknown seismic faults in the Eastern Mediterranean Sea basin.

\section{A comparison of ultra low frequency activity above the boundaries of tectonic plates with significant $(M \geq 5)$ earth- quakes}

We compared times of occurrence of $M \geq 5$ EQs with the times of intense ULF events occurrence in all cases examined in the previous section (Central America, Indonesia and the Eastern Mediterranean) and we found that many the ULF events were detected at times intermediated between successive EQs in the region examined. Therefore we may infer that the ULF radiation observed by DEMETER/ICE above the boundaries of tectonic plates emitted from an EQ preparation region either prior or after a significant $(\mathrm{M} \geq 5)$ earthquake.

\section{Discussion and Conclusions}

This paper aims to validate the hypothesis that the ULF wave activity is stronger above regions of high seismicity, and in particular at the boundaries of the tectonic plates, compared to the ULF wave activity detected above adjacent regions, and therefore is (mostly) a seismic-related phenomenon.

In order to verify the above hypothesis, the energy of the electric field component Ez of the ULF radiation being recorded by the DEMETER satellite, over seismically active regions, was estimated for a period of four years (20062009) and for satellite night-side satellite obits were considered. In particular, we compared the ULF wave activity observed by DEMETER above boundaries of the tectonic plates, such as such as Greece, Central America, Indonesia and the Eastern Mediterranean basin, with the ULF wave activity detected above adjacent regions and we found the following results: i) the EM ULF energy observed above the representative boundaries of tectonic plates was persistently higher than that observed above all the adjacent to the boundaries regions examined; ii) the most intensive electromagnetic ULF wave radiation was is recorded during satellite trajectories passing near or just above seismic faults; iii) the ULF wave activity above the boundaries of tectonic plates examined was persistently higher than that above their adjacent regions in each of the succes-
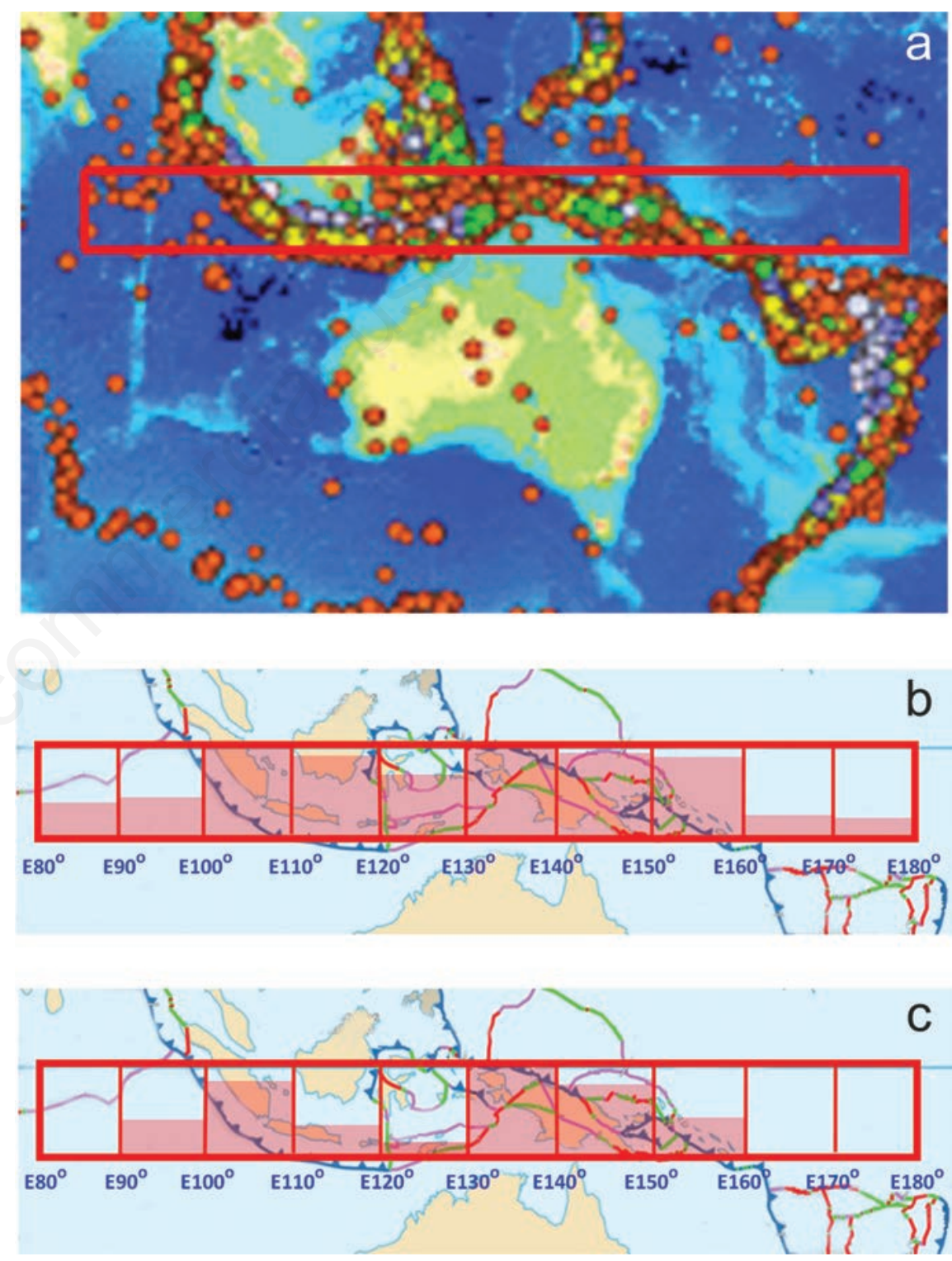

Figure 7. A) Seismicity map of Indonesia for the years 2000-2009 illustrating earthquakes of magnitude $M>4.5$. B) Normalized energy of ultra low frequency electromagnetic radiation within $10^{\circ}$ longitude divisions acquired by the DEMETER satellite for the years 2006-2009 with values $\geq 0.06(\mathrm{mV} / \mathrm{m})^{2}$. C) As in panel B) but for values $\geq 0.12$ $(\mathrm{mV} / \mathrm{m})^{2}$. 
sive years 2006-2009 (not only during the total period 2006-2009); iv) many ULF events observed by DEMETER/ICE above the boundaries of tectonic plates were observed either prior or after a significant $(M \geq 5)$ earthquakes; v) higher electromagnetic radiation was detected in a region above the northern-western Greek Arc (R1) than above the adjacent region including Athens and its urban area.

Taking into account the findings of this research, the critical question What is the possible contribution of earthquakes, human activities and other natural phenomena to the enhanced ULF wave activity in the topside ionosphere above the regions examined in this study? can be answered as following.

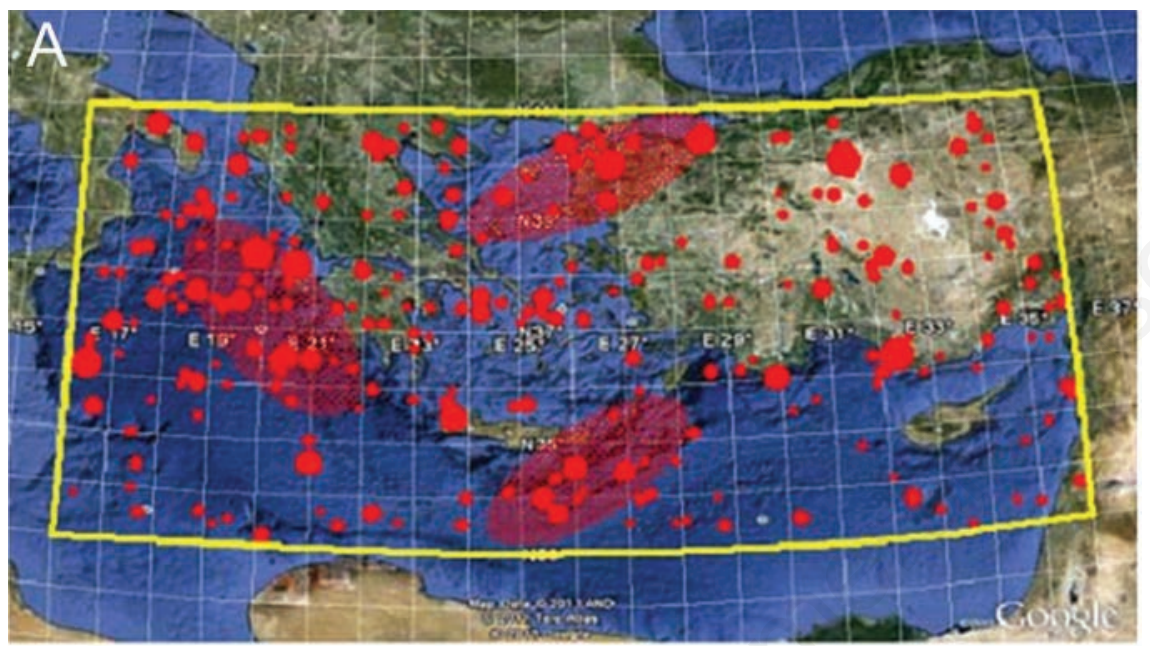

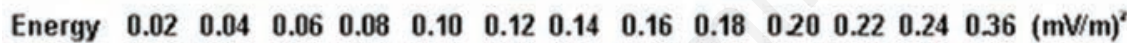
Symbol
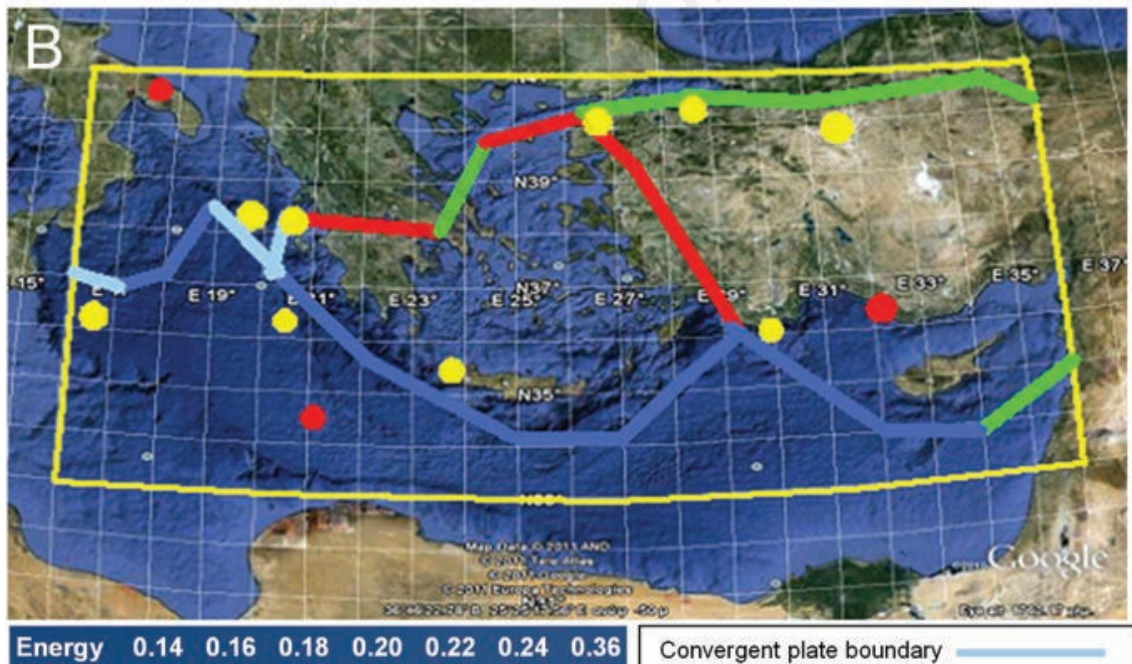
$(\mathrm{mV} / \mathrm{m})^{2}$ $\begin{array}{lllllll}0.14 & 0.16 & 0.18 & 0.20 & 0.22 & 0.24 & 0.36\end{array}$ Symbol

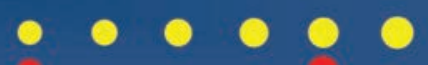

Convergent plate boundary

Divergent plate boundary

Transform plate boundary

Subduction zone

Figure 8. A) Location and energy of the ultra low frequency electromagnetic radiation acquired by the DEMETER satellite for the years 2006-2009 in Eastern Mediterranean Basin, with values $\geq 0.02(\mathrm{mV} / \mathrm{m})^{2}$. B) As in panel A) but for energy values $\geq 0.14$ $(\mathrm{mV} / \mathrm{m})^{2}$. ty), not with a phenomenon directly related with global or large scale natural phenomena (for instance, geomagnetic disturbances or solar wind impacts). Anagnostopoulos and Papandreou ${ }^{24}$ presented a period with a strong correlation of geomagnetic storms with earthquake occurrence time, but they noted that the possible causal relation of these two phenomena depends most probably on special geological conditions. Furthermore, we infer that, most probably global phenomena only cannot explain the systematic local differentiation of the ULF radiation near the boundaries of the tectonic plates. This conclusion is greatly supported by the permanent character of the systematic local variation found at various sites on the globe for a time interval as long as four years.

Bearing in mind the results presented here, we believe that this research work greatly supports the hypothesis that the ULF EM radiation observed in topside ionosphere is mostly emitted from seismically active areas. Molchanov ${ }^{25}$ and Freund and Pilorz ${ }^{26}$ have proposed physical mechanisms to explain the ULF EM radiation, but a choice between them cannot be based on the results of this study.

Furthermore, in the present study we found that many ULF events observed by DEMETER/ICE above the boundaries of tectonic plates were observed either prior or after a significant $(M \geq 5)$ earthquake. At this point, it is worth noting the temporal variation of the ULF electromagnetic radiation found by Athanasiou et al. ${ }^{18}$ in the case of the catastrophic Haiti earthquake, as revealed by the analysis of DEMETER/ICE data. Athanasiou $e t$ $a l .{ }^{18}$ showed that a significant increase of the ULF electromagnetic radiation started about $\sim 25$ days before the catastrophic Haiti earthquake, and then it gradually decreased within $\sim 25$ days after the main shock. The gradual increase (decrease) of the ULF radiated energy for 25 days before (after) the time of the main foreshock in Haiti not only supported previous studies which suggested that the ULF electromagnetic radiation is an earthquake precursor signal, but it showed that the duration of ULF EM radiation is detectable for a long time period in the case of some strong EQs, such as the 2010 Haiti EQ. These results may suggest that EQ-related ULF emission is a semi-permanent physical phenomenon. of course, further work is needed to elaborate a possible standard and probably a more detailed pattern of the ULF electromagnetic radiation temporal variation. We also work on the precise statistical evaluation of DEMETER ULF events, which are detectable above the boundaries of tectonic plates; these results will be presented in a future paper under preparation.

The presence of the ULF electromagnetic radiation during long time periods either before or after large EQs is consistent with the 
statistical results of Zhang et al. ${ }^{27}$ who reported that according to their criteria applied to 69 time intervals, beginning 7 days before and ending 1 day after the day of a $M \geq 7.0 \mathrm{EQ}$ between January 2005 - February 2010, a percentage of $46 \%$ EQs (32) was accompanied by low frequency (ULF/ELF) perturbations. Furthermore we note that we examined DEMETER/ICE data near times of the $68 \mathrm{M} \geq 7.0$ and we found that several of the EQs were accompanied by ULF events for periods much longer than 7 days before the EQ occurrence times, which were considered by Zhang et al. ${ }^{27}$ For instance, such an EQ was that which occurred in Chile in 2010.

We also note that the implemented methodology used in our study is capable of detecting even small seismic areas during the pre-earthquake activity, as one can see in the case of the Greek Arc examined in Figure 2, and we hope that we will be able to provide more detailed information on the spatiotemporal variations of the EQ-related ULF electromagnetic radiation in the near future and further contribute to EQ prediction research.

\section{References}

1. Varotsos P, Alexopoulos K, Lazaridou M, Nagao T. Earthquake predictions issued in Greece by seismic electric signals since February 6, 1990. Tectonophysics 1993;224:269-88.

2. Parrot M. Statistical study of ELF/VLF emissions recorded by a low altitude satellite during seismic activity. J Geophys Res 1994;99:23339-47.

3. Pulinets SA, Boyarchuk KA. Ionospheric precursors of earthquakes. Berlin, Heidelberg, New York: Springer; 2004. pp 1-287.

4. Hayakawa M, Kasahara Y, Nakamura T, et al. On the correlation between ionospheric perturbations as detected by subionospheric VLF/LF signals and earthquakes as characterized by seismic intensity. J Atmos Solar-Terr Phys 2010;72:982-7.

5 . Pulinets $S$. The synergy of earthquake precursors. Earthquake Sci 2011;24:535-48.
6. Anagnostopoulos G, Vassiliadis E, Pulinets S. Characteristics of flux-time profiles, temporal evolution, and spatial distribution of radiation-belt electron precipitation bursts in the upper ionosphere before great and giant earthquakes. Ann Geophys 2012;55:21-36.

7. Pulinets S, Ouzounov D. Lithosphereatmosphere-ionosphere coupling (LAIC) model-A unified concept for earthquake precursors validation. J Asian Sci 2011;41: 371-82.

8. Gokhberg MB, Kustov VA, Liperovsky VA. About perturbations in the ionospheric Fregion before strong earthquakes. Izv Akas Nauk SSSR Fiz Zemli 1988;N4:12-20. [in Russian].

9. Molchanov OA, Fedorov E, Schekotov A, et al. Lithosphere-atmosphere-ionosphere coupling as governing mechanism for preseismic short-term events in atmosphere and ionosphere. Nat Hazards Earth Syst Sci 2004;4:757-67.

10. Cress 00, Brady BT, Rowell GA. Source of electromagnetic radiation from fractures of rock samples in the laboratory. Geophys Res Lett 1987;14:331.

11. Enomoto Y, Hashimoto H. Emission of charged particles from indentation fracture of rocks. Nature 1990;346:641.

12. Parrot M, Achache J, Berthelier JJ, et al. High frequency seismo-electromagnetic effects. Phys Earth Planet Inter 1993;77:65.

13. Parrot M. Anomalous seismic phenomena: view from space. In: Hayakawa M, ed. Electromagnetic phenomena associated with earthquakes. Trivandrum: Transworld Research Network; 2009. pp 205-233.

14. Hayakawa M, Hattori K, Ohta K. Monitoring of ULF (ultra-low-frequency) geomagnetic variations associated with earthquakes. Sensors 2007;7:1108-22.

15. Freund FT. Earthquake forewarning - a multidisciplinary challenge from the ground up to space. Acta Geophys 2013;61:775-807.

16. Bortnik J, Bleier T. Full wave calculation of the source characteristics of seismogenic electromagnetic signals as observed at LE0 satellite altitudes. Eos Trans AGU 2004;85:T51B-0453.
17. Parrot M, Berthelier JJ, Lebreton JP, et al. Examples of unusual ionospheric observations made by the DEMETER satellite over seismic regions. Phys Chem Earth 2006;31:486-95.

18. Athanasiou MA, Anagnostopoulos GC, Iliopoulos AC, et al. Enhanced ULF radiation observed by DEMETER two months around the strong 2010 Haiti earthquake. Nat Hazards Earth Syst Sci 2011;11:1091-8.

19. Henderson TR, Sonwalker VS, Helliwell RA, et al. A search for ELF/VLF emissions induced by earthquakes as observed in the ionosphere by the DE-2 satellite. J Geophys Res 1993;98:503-9514.

20. Nemec F, Santolík 0, Parrot M. Decrease of intensity of ELF/VLF waves observed in the upper ionosphere close to earthquakes: A statistical study. J Geophys Res 2009;114: A04303.

21. Masci F. Brief communication on the recent reaffirmation of ULF magnetic earthquakes precursors. Nat Hazards Earth Syst Sci 2011;11:2193-8.

22. Berthelier JJ, Godefroy M, Leblanc F, et al. ICE, The electric field experiment on DEMETER. Planet Space Sci 2006;545:456-71.

23. Athanasiou MA, Pavlos GP. SVD analysis of the magnetospheric $\mathrm{AE}$ index time series and comparison with low dimensional chaotic dynamics. Nonlin Proces Geophys 2001;8:95-125.

24. Anagnostopoulos G, Papandreou A. Space conditions during a month of a sequence of six strong $\mathrm{M}>6$.8ending with the tsunami of 26 December 2004. Nat Haz Earth Syst Sci 2012;12:1551-9.

25. Molchanov OA. Underlying mechanism of precursory activity from analysis of upward earthquake migration. Nat Hazards Earth Syst Sci 2011;11:135-43.

26. Freund F, Pilorz S. Electric currents in the earth crust and the generation of pre-earthquake ULF signals. In: Hayakawa M, ed. Frontier of earthquake prediction studies. Tokyo: Nippon Shuppan; 2012. pp 464-508.

27. Zhang X, Fidani C, Huang J, et al. Burst increases of precipitating electrons recorded by the DEMETER satellite before strong earthquakes. Nat Hazards Earth Syst Sci 2013;13:197-209. 